\title{
Notch3 is involved in the proliferation of renal cancer cells via regulation of cell cycle progression and HIF-2 $\alpha$
}

\author{
QIPENG HAN $^{1,2}$, FANGZHU HAN ${ }^{3}$, YISHENG FAN ${ }^{2}$, BOWEN LIAN $^{3}$, JINYANG XIAO $^{3}$, \\ WEI SUN ${ }^{2}$, DONGBING HAN ${ }^{2}$, HONGBO KOU ${ }^{2}, \mathrm{CHUNYAN} \mathrm{LI}^{3}$ and BIN WU ${ }^{1}$ \\ ${ }^{1}$ Department of Urinary Surgery, Shengjing Hospital of China Medical University, Shenyang, Liaoning 110004; \\ ${ }^{2}$ Department of Urinary Surgery, General Hospital of Northern Theater Command, Shenyang, Liaoning 110001; \\ ${ }^{3}$ Center of Science Experiments, China Medical University, Shenyang, Liaoning 110122, P.R. China
}

Received March 2, 2020; Accepted September 15, 2020

DOI: $10.3892 / \mathrm{ol} .2020 .12242$

\begin{abstract}
Renal cell carcinoma (RCC) is one of the most common malignant tumors of the urinary system. Although deregulation of the Notch signaling pathway is common in $\mathrm{RCC}$ and is involved in the tumorigenic process, the exact role of Notch3 and its underlying molecular mechanism in RCC, particularly in hypoxia, remain unknown. In the present study, RO4929097, a Notch3 inhibitor, was used to alter NICD3 expression. A Cell Counting Kit- 8 assay, EdU incorporation assay, colony formation assay, flow cytometry and western blot analysis were used to investigate the effects of altered NICD3 expression on cell proliferation, cell cycle progression and HIF- $2 \alpha$ protein expression. The results of western blot analysis showed that RO4929097 dose-dependently decreased the expression of Notch3 intracellular domain (NICD3) in 786-O and ACHN cells, which originate from clear cell RCC (ccRCC). The results of the Cell Counting Kit-8, EdU incorporation and colony formation assays demonstrated that downregulation of NICD3 significantly suppressed cell proliferation in both normoxia and hypoxia. In addition, flow cytometry and western blot analysis demonstrated that hypoxia $\left(2 \% \mathrm{O}_{2}\right)$ promoted cell cycle progression in ccRCC cells with the increased expression of $\mathrm{G}_{1}-\mathrm{S}$ transition-associated proteins, namely cyclin-dependent kinase (CDK)4 and cyclin D1, while downregulation of NICD3 exerted negative effects on cell cycle progression, and the expression levels of CDK4 and cyclin D1. Furthermore, western blot analysis revealed
\end{abstract}

Correspondence to: Professor Bin Wu, Department of Urinary Surgery, Shengjing Hospital of China Medical University, 36 Sanhao Street, Shenyang, Liaoning 110004, P.R. China

E-mail: wbin_usd@sina.com

Professor Chunyan Li, Center of Science Experiments, China Medical University, 77 Puhe Road, Shenyang, Liaoning 110122, P.R. China

E-mail: chyli@cmu.edu.cn

Key words: Notch3, clear cell renal cell carcinoma, cell proliferation, cell cycle, HIF-2 $\alpha$ that $2 \% \mathrm{O}_{2}$-induced upregulated hypoxia-inducible factor- $2 \alpha$ (HIF-2 $\alpha$ ) expression decreased following downregulation of NICD3 in 786-O and ACHN cells. Following transfection of the vector containing the NICD3 coding sequence, HIF-2 $\alpha$, CDK4, cyclin D1 and proliferating cell nuclear antigen expression, that were inhibited by RO4929097 in hypoxia, were rescued. Collectively, the results of the present study suggest that Notch3 is closely associated with the cell proliferation of ccRCC cells by regulating the cell cycle and HIF- $2 \alpha$.

\section{Introduction}

Renal cell carcinoma (RCC) is a complex, multifaceted malignant disease comprising different and specific entities, with over two-thirds of all cases being clear cell RCC (ccRCC) (1). Of all ccRCCs cases, $60-80 \%$ are considered to be associated with the biallelic inactivation of the Von Hippel Lindau (VHL) gene, which causes aberrant accumulation of hypoxia-inducible factor (HIF) (2). In addition, HIF is a critical component of several proteins that constitute the cellular machinery for adaption to hypoxia, which is the result of rapid cell proliferation and poor vascularization of solid tumors (3). Although previous evidence from genetic and biological studies indicates that hypoxia-associated pathways play key roles in the development and progression of renal cancer (4), the underlying molecular mechanism is complex and remains elusive.

As a highly conserved developmental signaling pathway, deregulated Notch signaling has been reported to be associated with tumorigenesis. The core Notch signaling pathway is composed of five ligands (Jagged-1 and -2 and $\delta$-like-1, -3 , and -4) and four receptors (Notch1-4). The binding of a ligand with a Notch receptor results in two proteolytic cleavages of the receptor, which leads to the release of the Notch intracellular domain (NICD). Subsequently, NICD translocates into the nucleus, where it interacts with the DNA-binding factors [CBF1/RBP-J, Su (H), Rbpsuh and Lag-1, CSL] to regulate the expression of downstream genes $(5,6)$. Clinical studies have demonstrated that Notch1 signaling is activated in ccRCC and may be a useful biomarker for prognosis $(7,8)$, whereas treatment with Notch1 inhibitors may inhibit the progression of ccRCC (9). While the Notch1 signaling pathway has been 
demonstrated to be involved in the progression of ccRCC, less is known on whether and how Notch regulates the cellular hypoxic response, particularly Notch3, the structure and function of which differs from those of the other three Notch receptors (10). In the present study, RO4929097, a $\gamma$-secretase inhibitor that inhibits NICD expression, thereby decreasing the expression of the downstream Notch targets (11), was used to alter NICD3 expression. The present study aimed to investigate the effects of altered NICD3 expression on cell proliferation, cell cycle progression and HIF- $2 \alpha$ protein expression, which may prove to be of value in the treatment of RCC.

\section{Materials and methods}

Cell lines and cell culture. The human ccRCC cell lines, 786-O and ACHN were purchased from American Type Culture Collection and maintained in RPMI-1640 medium or minimal essential medium (MEM) supplemented with $10 \%$ fetal bovine serum (all purchased from HyClone; Cytiva), respectively. 786-O and ACHN cells were treated with or without RO4929097 (cat. no. HY-11102; MCE), and were cultured under normoxic $\left(21 \% \mathrm{O}_{2}, 37^{\circ} \mathrm{C}\right.$ and $\left.5 \% \mathrm{CO}_{2}\right)$ or hypoxic $\left(2 \% \mathrm{O}_{2}, 37^{\circ} \mathrm{C}\right.$ and $\left.5 \% \mathrm{CO}_{2}\right)$ conditions for $48 \mathrm{~h}$, or with $200 \mu \mathrm{M}$ cobalt chloride $\left(\mathrm{CoCl}_{2}\right)$ (cat. no. C7300; Beijing Solarbio Science \& Technology Co., Ltd.) under $21 \% \mathrm{O}_{2}, 37^{\circ} \mathrm{C}$ and $5 \% \mathrm{CO}_{2}$ condition for $48 \mathrm{~h}$.

Cell Counting Kit-8 (CCK-8) assay. 786-O and ACHN cells were seeded into 96 -well plates at a density of 10,000 cells/well and cultured under normoxic or hypoxic conditions at $37^{\circ} \mathrm{C}$ for $48 \mathrm{~h}$. Then, according to the manufacturer's protocol, the cell proliferation rates of 786-O and $\mathrm{ACHN}$ were subsequently analyzed via the CCK-8 assay (cat. no. DJDB4000X; Dojindo Molecular Technologies, Inc.).

EdU assay. EdU incorporation assay was performed using the Cell-Light ${ }^{\mathrm{TM}}$ EdU Apollo ${ }^{\circledR} 488$ In Vitro Flow Cytometry kit (cat. no. C10310-3; Guangzhou Ribobio Co., Ltd.), according to the manufacturer's protocol. Briefly, 786-O and ACHN cells were respectively cultured in RPMI-1640 and MEM medium supplemented with $10 \mu \mathrm{MEdU}$ for $2 \mathrm{~h}$ at $37^{\circ} \mathrm{C}$, and washed with cold phosphate buffered saline (PBS) containing $1 \%$ bovine serum albumin (Beijing Solarbio Science \& Technology Co., Ltd.) for three times. Cells were resuspended in $500 \mu \mathrm{l}$ of $1 \mathrm{X}$ Apollo reaction buffer and subsequently incubated at room temperature for $30 \mathrm{~min}$. 786-O and ACHN cells were re-washed twice with PBS containing $0.5 \%$ Triton X-100, stained with $1 \mathrm{X}$ Hoechst 33342 reaction buffer for $5 \mathrm{~min}$ at room temperature, re-washed twice with PBS containing $0.5 \%$ Triton X-100, and subsequently added to $500 \mu \mathrm{l}$ PBS. Cells were observed under an inverted immunofluorescence microscope at x10 magnification [IX70/SPOT RT-KE (color); Olympus Corporation/Diagnostic Instruments Inc.] and EdU-positive cells were counted using ImageJ software (version 1.52; National Institute of Health).

Colony formation assay. 786-O and ACHN cells were trypsinized and seeded into 6-well plates at a density of 500 cells/well. The RPMI-1640 and MEM medium with $10 \%$ fetal bovine serum were replaced with fresh media every $48 \mathrm{~h}$, and cells were cultured at $37^{\circ} \mathrm{C}$ under normoxic and hypoxic conditions, respectively. After 10 days, the size of colonies was observed in the control group (untreated cells). When the colonies size reached size $>50$ cells, the medium was removed and the formed colonies were stained with $10 \%$ methylene blue (Beijing Solarbio Science \& Technology Co., Ltd.) in $70 \%$ ethanol at room temperature for $5 \mathrm{~min}$. The staining solution was removed and washed three times with PBS to remove background staining. Triplicate wells were set up for each condition, with or without RO4929097 under normoxic or hypoxic conditions, and cells were observed under a light microscope at x2 magnification [SZX12/SPOT RT-KE (color); Olympus Corporation/Diagnostic Instruments Inc.]. The integrated optical density (IOD) of each well was analyzed using Image-Pro Plus 6.0 software (Media Cybernetics, Inc.).

Cell cycle analysis. Cell lines 786-O and ACHN with or without RO4929097 in normoxia or hypoxia were collected and washed with PBS by centrifugation at $60 \mathrm{x}$ g for $5 \mathrm{~min}$ at $4^{\circ} \mathrm{C}$, prior to fixation in $75 \%$ alcohol overnight at $-20^{\circ} \mathrm{C}$. Cells were washed three times with cold PBS and resuspended in $1 \mathrm{ml}$ PBS containing $1 \%$ Triton $\mathrm{X}-100,40 \mu \mathrm{g}$ propidium iodide and $100 \mu \mathrm{g}$ RNase A (both from Sigma-Aldrich; Merck $\mathrm{KGaA}$ ), and incubated at $4^{\circ} \mathrm{C}$ for at least $30 \mathrm{~min}$. The staining solution was then removed and cells were washed twice with PBS. Samples were resuspended in $0.5 \mathrm{ml}$ PBS and analyzed for DNA contents using a flow cytometer (FACSCalibur; BD Biosciences) and ModFit LT software (version 3.3; FACSCalibur; BD Biosciences).

Vector construction and transfection. The coding sequence of NICD3 was cloned using a pCLE NICD3 construct (cat. no. 26894; Addgene, Inc.), amplified and re-cloned into a p3xFLAG-CMV-14 vector (cat. no. E7908; Sigma-Aldrich; Merck KGaA). The plasmid DNAs were sequence-confirmed and named as p3xFLAG-CMV-14-NICD. For the transfection experiments, according to the manufacturer's instructions, $786-\mathrm{O}$ and ACHN cells $\left(2 \times 10^{5}\right.$ cells/well) were seeded in 6-well plates overnight, then transfected with p3xFLaG-CMV-14 vector as the control or p3xFLaG-CMV-14-NICD vector $(2 \mu \mathrm{g} / \mathrm{ml})$ using Lipofectamine ${ }^{\circledR} 3000$ (cat. no. L3000015; Thermo Fisher Scientific, Inc.). After 24 h post-transfection, RO4929097 was added to cell culture wells. Subsequently, the cells were cultured under hypoxic conditions for $48 \mathrm{~h}$, and the cells were harvested for further analysis.

Western blotting. 786-O and ACHN cells were lysed using RIPA lysis buffer (cat. no. P0013C; Beyotime Institute of Biotechnology). Cell extracts were collected via centrifugation and protein concentration was measured by BCA method. Subsequently, $50 \mu \mathrm{g}$ protein per lane was separated by SDS-PAGE on a $10 \%$ gel and transferred to PVDF membranes. The membranes were blocked with 5\% non-fat milk for $2 \mathrm{~h}$ at room temperature, and then incubated with the following primary antibodies: Rabbit polyclonal anti-HIF-2 (1:500; cat. no. NB100-122; Novus Biologicals, LLC), rabbit polyclonal anti-Notch3 (1:500; cat. no. ab23426; Abcam), mouse monoclonal anti-cyclinD1 (1:500; cat. no. 60186-1-Ig; ProteinTech Group, Inc.), rabbit polyclonal anti-CDK4 (1:1,000; cat. no. YT5198; http://www.immunoway.com/), 
rabbit polyclonal anti-PCNA (1:1,000; cat. no. ab152112; Abcam) and mouse monoclonal anti- $\beta$-actin $(1: 1,000$; cat. no. AF0003; Beyotime Institute of Biotechnology) at $4{ }^{\circ} \mathrm{C}$ overnight. Following the primary incubation, membranes were incubated with horseradish peroxidase-conjugated goat anti-rabbit $(1: 10,000)$ or anti-mouse IgG $(1: 10,000)$ (cat. nos. A0208 and A0216, respectively; both from Beyotime Institute of Biotechnology) secondary antibodies at room temperature for $2 \mathrm{~h}$. Protein bands were visualized using the chemiluminescent reagent SuperSignal West Pico Chemiluminescent Substrate (Thermo Fisher Scientific, Inc.). Densitometry values were normalized to levels of $\beta$-actin. Quantitation analysis for western blot were performed using ImageJ software (version 1.52; National Institute of Health).

Statistical analysis. Statistical analysis was performed using (version 6.0; GraphPad Software, Inc.). All experiments were performed in triplicate and data are presented as the mean \pm standard deviation. One-way analysis of variance, followed by Tukey's post hoc test was used to compare differences between multiple groups. GraphPad Prism 6.0 was used to create the histograms. $\mathrm{P}<0.05$ was considered to indicate a statistically significant difference.

\section{Results}

RO4929097 dose-dependently inhibits NICD3 expression and decreases ccRCC cell proliferation in normoxia and hypoxia. Aberrant cell proliferation is the main biological characteristic of cancer (12), and is affected by the tumor microenvironment, including the $\mathrm{O}_{2}$ concentration around cancer cells (13). In the present study, cells were treated with or without RO4929097 for $48 \mathrm{~h}$. Western blot analysis demonstrated that NICD3 expression decreased with increasing concentration of RO4929097 in 786-O and ACHN cells (Fig. 1A). Moreover, after the treatment with $20 \mu \mathrm{M}$ RO4929097 for $48 \mathrm{~h}$, not many dead cells were obviously observed via invert-microscope, suggesting that the direct cytotoxicity of RO4929097 to cells was low. The CCK-8 assay was performed to determine whether inhibition of Notch3 decreased cell proliferation. As presented in Fig. 1B, a significant increase in proliferation was induced by hypoxia in the control groups of $786-\mathrm{O}$ cells $(\mathrm{P}<0.01)$ but not ACHN cells, and the increases weren't significant in the treatment groups of two cell lines. However, the proliferation of 786-O and ACHN cells was significantly inhibited by RO4929097 under normoxic and hypoxic conditions $(\mathrm{P}<0.05$ in 786-O in normoxia; $\mathrm{P}<0.01$ in $786-\mathrm{O}$ in hypoxia; $\mathrm{P}<0.01$ in $\mathrm{ACHN}$ in normoxia or hypoxia;). EdU incorporation assay was performed to validate the effect of RO4929097 or hypoxia on cell proliferation. The results demonstrated that the number of EdU-positive cells significantly increased in response to hypoxia in the control groups and the treatment groups of two cell lines (all $\mathrm{P}<0.01$ ), whereas the number of EdU-positive cells significantly decreased following RO4929097 treatment in normoxia and hypoxia (all $\mathrm{P}<0.05$ ) (Fig. 1C).

The colony formation assay is considered the gold standard for analyzing cell proliferation potential in cellular systems in vitro $(14,15)$. In the present study, $786-\mathrm{O}$ and ACHN cells were cultured under normoxic or hypoxic conditions for 10 days. At the end of the culture period, the cells derived from a single cell were separable and did not form a dense clone. Thus, the sum of the IOD of cells stained with methylene blue in each well was measured, rather than the number of colonies. The results demonstrated that under normoxic conditions, the sum of the IOD significantly decreased following RO4929097 treatment in $786-\mathrm{O}$ cells $(\mathrm{P}<0.01)$, but not in ACHN cells. Furthermore, under hypoxic conditions, the sum of the IOD significantly increased in both 786-O and ACHN cells $(\mathrm{P}<0.05$ in 786-O and $\mathrm{P}<0.01$ in $\mathrm{ACHN})$, the effects of which were reversed following RO4929097 treatment $(\mathrm{P}<0.05$ in $786-\mathrm{O}$ and $\mathrm{P}<0.01$ in ACHN) (Fig. 1D). Collectively, these results suggest that hypoxia promotes the proliferation of ccRCC cells in vitro, and inhibiting NICD3 expression may repress the proliferation of ccRCC cells under both normoxic and hypoxic conditions.

Downregulation of NICD3 inhibits RCC cell cycle progression via CDK4 and cyclin D1, under both normoxic and hypoxic conditions. Cell replication and division are tightly regulated by the cell cycle, and dysregulation of the cell cycle leads to aberrant cell proliferation in cancer (16). Cell cycle distribution was assessed to determine the molecular mechanism underlying the regulatory effect of Notch3 on the proliferation of ccRCC cells. As presented in Fig. 2A and B, hypoxia decreased the percentage of cells in the $G_{1}$ phase compared with that in normoxia in 786-O $(\mathrm{P}<0.01)$ but not $\mathrm{ACHN}$, and RO4929097 treatment significantly increased the percentage of cells in the $\mathrm{G}_{1}$ phase, under both normoxic (all $\left.\mathrm{P}<0.05\right)$ and hypoxic conditions (all $\mathrm{P}<0.01$ ). Furthermore, the increased range of the percentage of cells in the $G_{1}$ phase induced by RO4929097 in hypoxia was higher compared with that in normoxia.

The biological properties modulated by hypoxic signaling and Notch signaling pathways are due to the initial expression levels of a set of downstream genes, such as cyclin D1, CDK4, $\mathrm{P}^{21}$ and so on (2,17-21). For example, hypoxic signaling and Notch signaling regulated the migration and invasion of breast cancer via their regulation to the targets, snail and slug (21). Thus, the expression levels of cyclin D1 and CDK4, which regulate $G_{1}-S$ transition $(22,23)$, were detected via western blotting. Western blot analysis demonstrated that hypoxia upregulated the expression of cyclin D1 and CDK4 of the control groups (all $\mathrm{P}<0.01$ ). After treatment RO4929097, their expressions were downregulated in no matter normoxia (all $\mathrm{P}<0.05$ ) or hypoxia (all $\mathrm{P}<0.01$ ) (Fig. 2C). Given that an increasing number of cells in the $\mathrm{G}_{1}$ phase indicates low proliferation $(24,25)$, consistent with those of cell cycle analysis, the results suggested that downregulation of NICD3 may decrease cell proliferation by regulating the cell cycle.

NICD3 overexpression rescues the expression of $H I F-2 \alpha$, CDK4, cyclin D1 and PCNA, which are inhibited by RO4929097 in hypoxia. A set of cellular responses, such as proliferation, drug resistance and metastasis, caused by low oxygen levels are mediated by HIFs $(3,4,13)$. HIF- $\alpha$ is an oxygen-dependent transcriptional activator, and three $\alpha$ subunits (HIF-1 $\alpha$, HIF-2 $\alpha$ and HIF-3 $\alpha$ ) have been identified (4). Several lines of investigation indicate that HIF- $2 \alpha$, but not HIF-1 $\alpha$, is upregulated in ccRCC, which promotes ccRCC procession $(26,27)$. In addition, HIF-1 $\alpha$ is not expressed in 786-O cells, which 
A

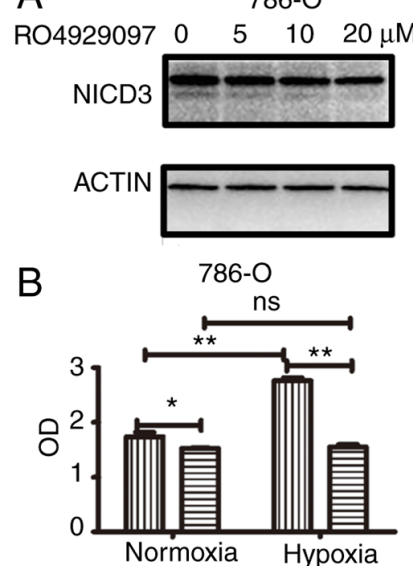

$\mathrm{ACHN}$
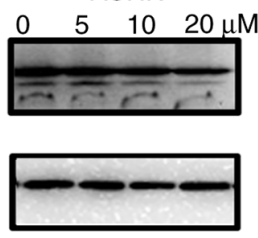

$\mathrm{ACHN}$

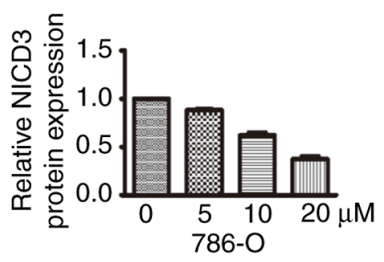

III Control
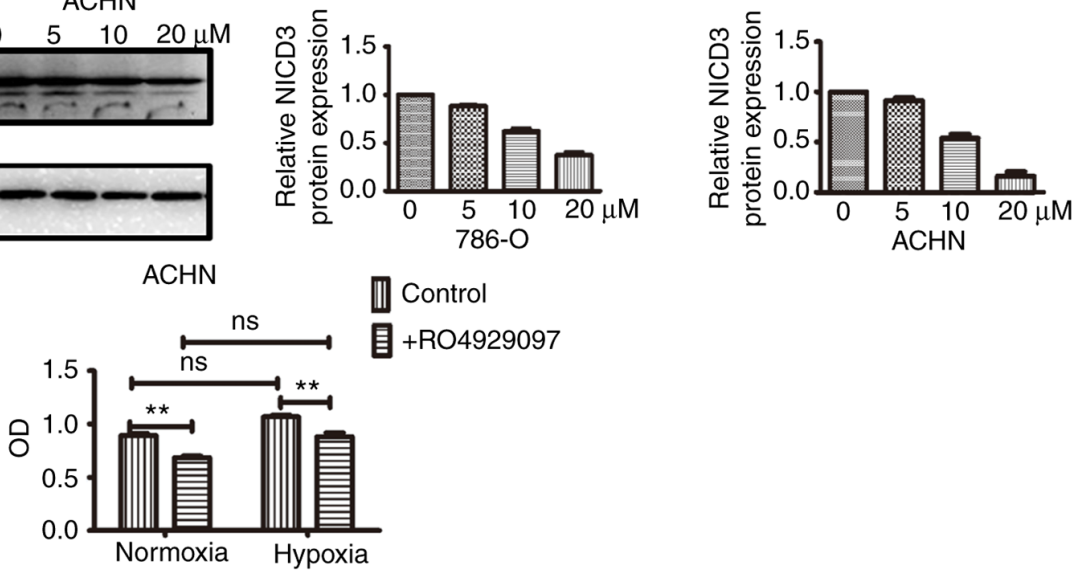

C

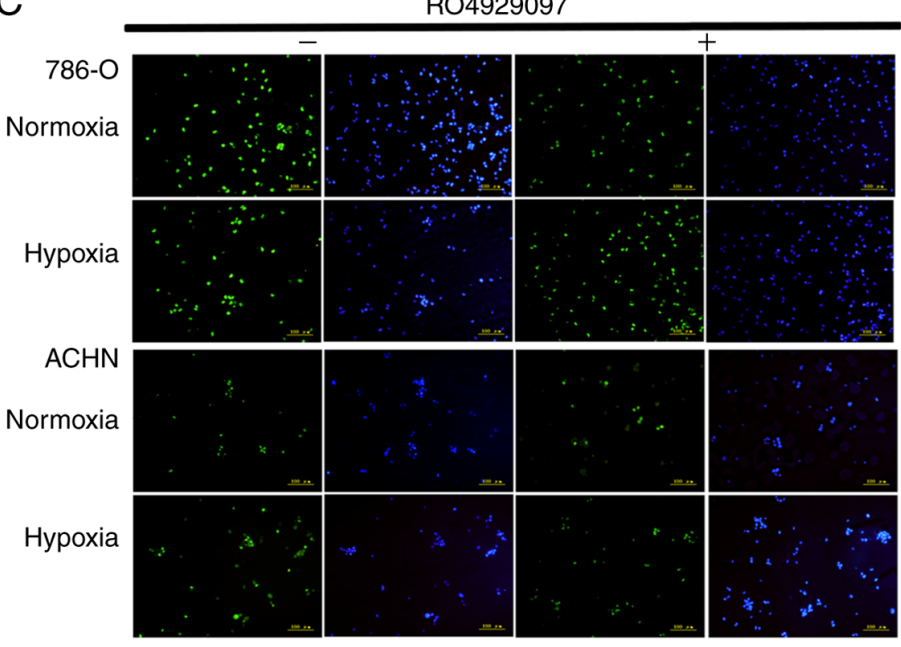

D
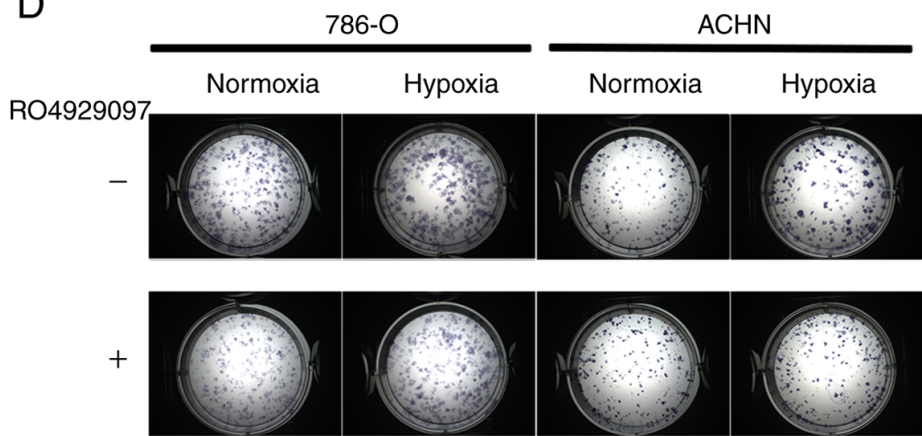
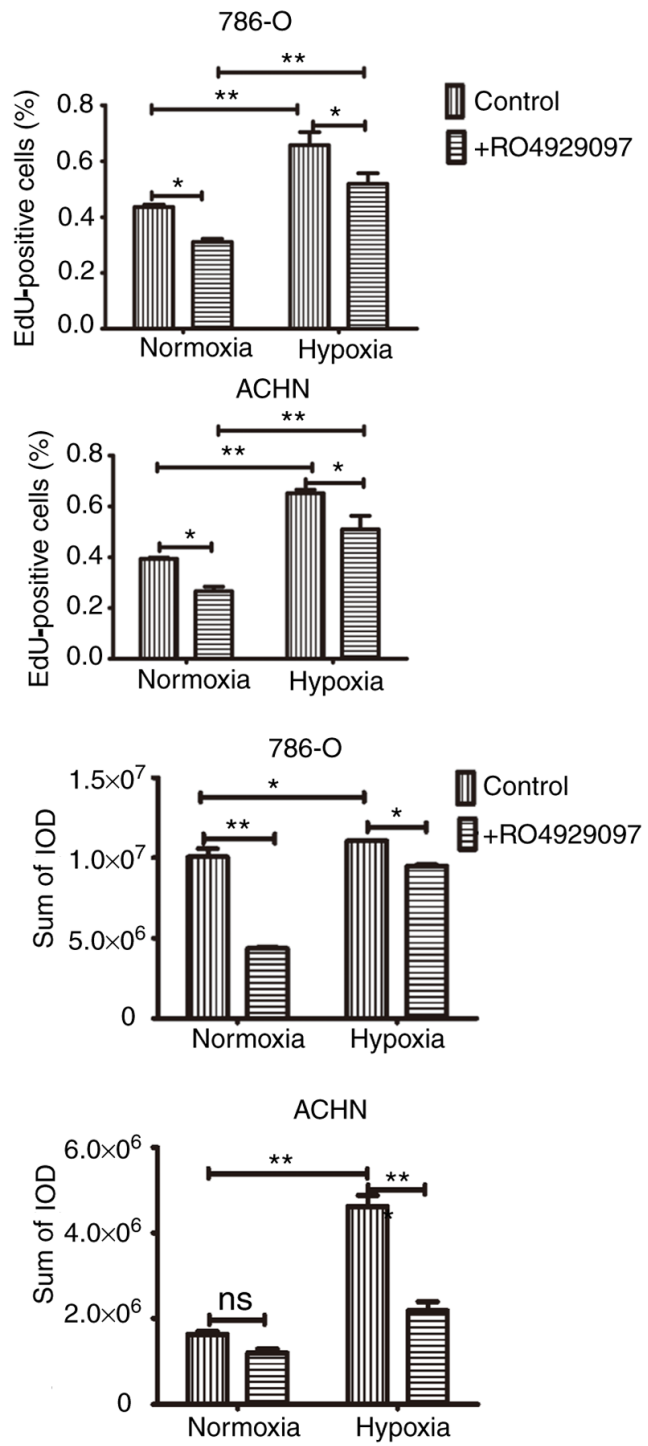

Figure 1. Proliferation analysis of 786-O and ACHN cells under normoxic or hypoxic conditions, with or without RO4929097. (A) Western blot analysis of NICD3 protein expression in 786-O and ACHN cells treated with RO4929097. Left, representative blot images. NICD3 bands, $90 \mathrm{kDa}$ and N3ICD with the transmembrane domain bands, $>90 \mathrm{kDa}$. Right, histograms of the relative protein expression. (B) Cell Counting Kit-8 assay was performed to assess cell proliferation. (C) EdU incorporation assay was performed to assess cell proliferation. Left, representative images of cells. Right, histograms presenting the numbers of EdU-positive cells counted using ImageJ software. (D) Analysis of cell proliferation with the colony formation assay. Left, representative images of cell colonies. Right, histograms of the IODs of methylene blue-stained cells measured using Image-Pro Plus 6.0 software. ${ }^{*} \mathrm{P}<0.05$, ${ }^{* *} \mathrm{P}<0.01$. NICD3, Notch3 intracellular domain; EdU, 5-Ethynyl-2'-deoxyuridine; IOD, integrated optical density; ns, not significant.

lack HIF-1 $\alpha$ mRNA (28). Previous studies have reported that HIFs interact with types of Notch in cancer, such as in breast cancer and prostate cancer $(29,30)$, thus the effect of hypoxia on Notch 3 expression and the effect of NICD 3 on HIF- $2 \alpha$ 
A
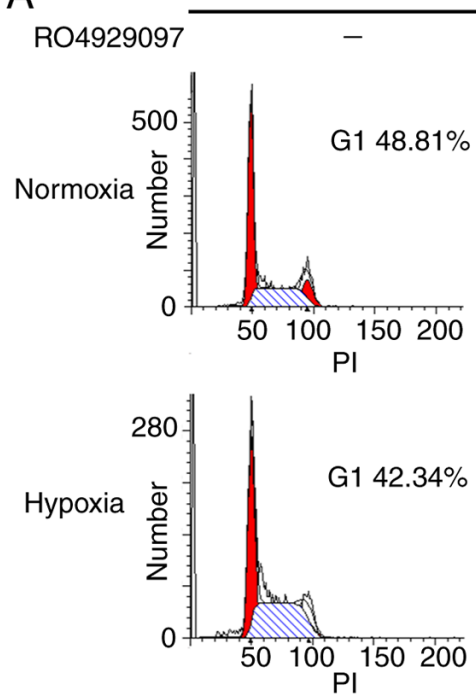

$786-\mathrm{O}$
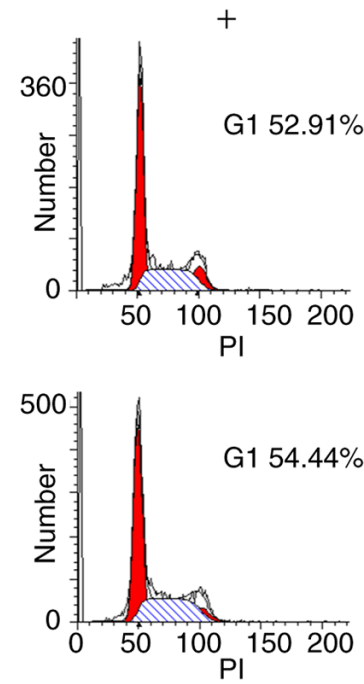
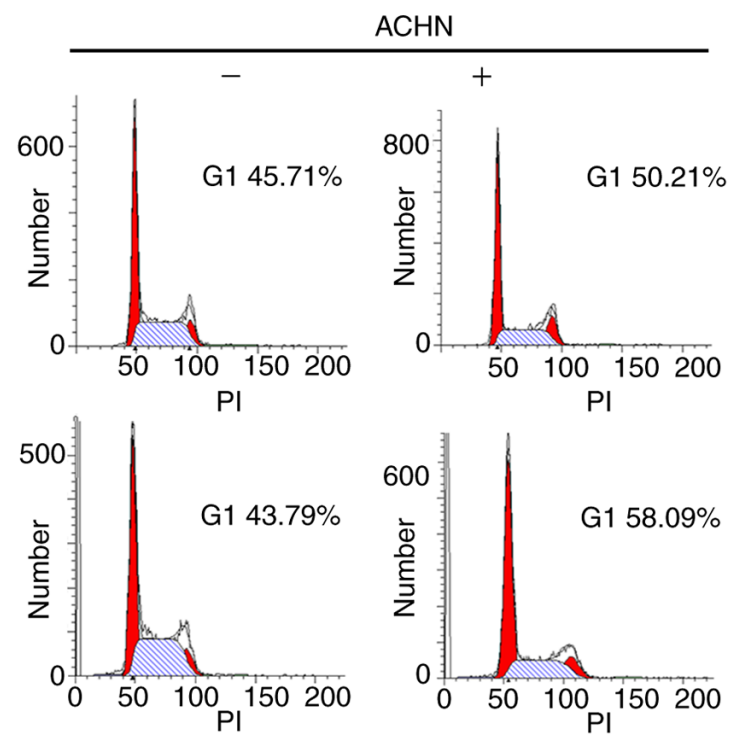

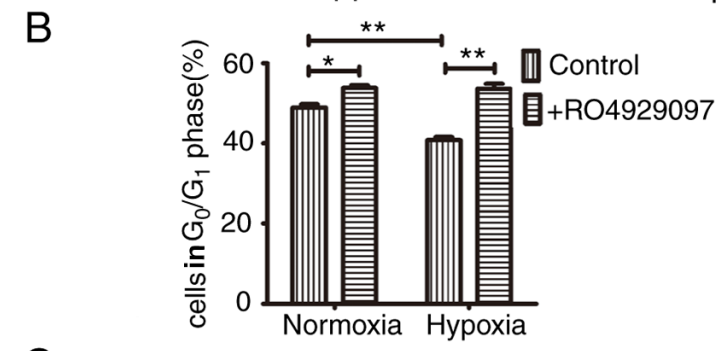

RO4929097 $\frac{\text { Normoxia }}{-++} \frac{\text { Hypoxia }}{-+}$
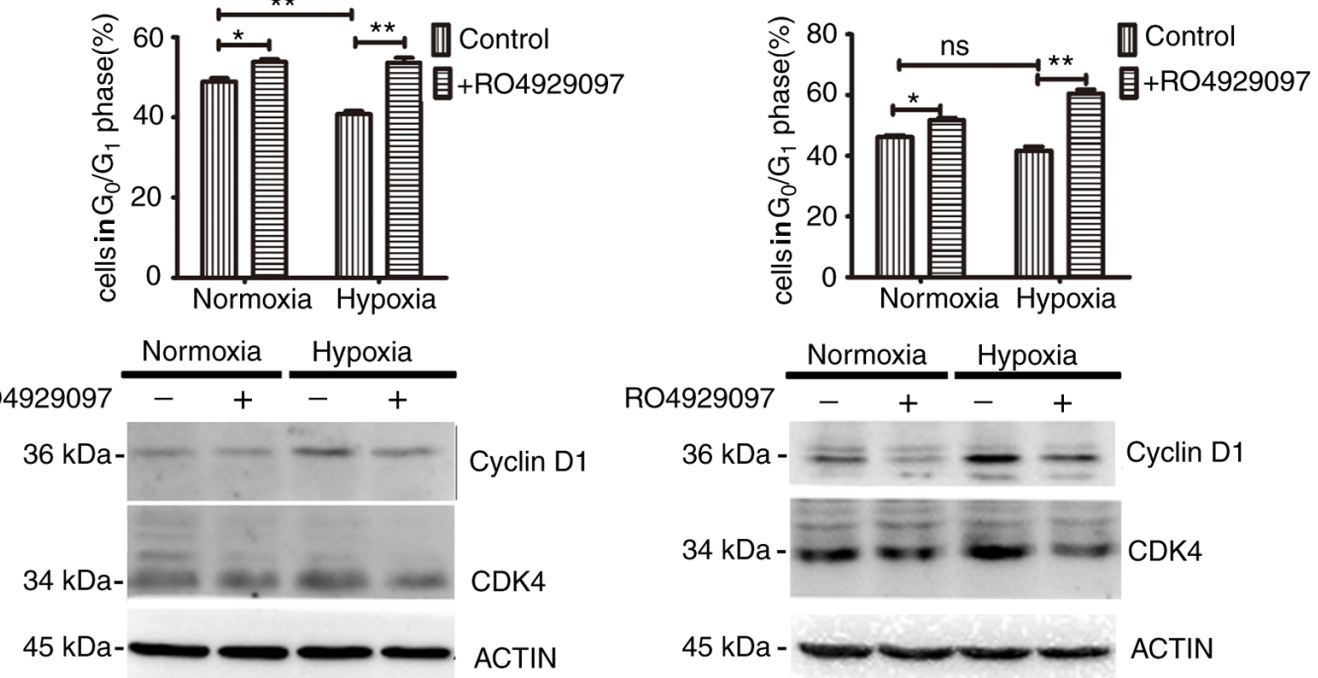

Normoxia
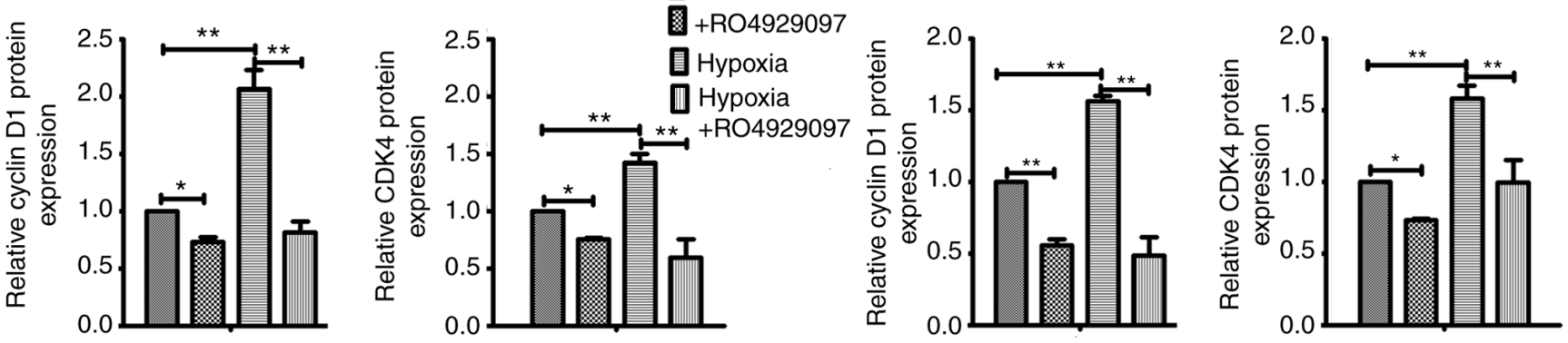

Figure 2. Cell cycle analysis of 786-O and ACHN cells under normoxic or hypoxic conditions. (A) Representative images of cell cycle distribution as assessed by flow cytometry. (B) Histograms representing the statistically significant difference between the control and treated samples. (C) Western blot analysis of cyclin D1 and CDK4 expression. Upper panels, representative blot images. Cyclin D1 bands, $36 \mathrm{kDa}$ and CDK4 bands, $34 \mathrm{kDa}$. The other bands are potentially the posttranslational modification or alternative splicing isoforms of cyclin $\mathrm{D} 1$ and $\mathrm{CDK} 4$. Lower panels, histograms of the relative protein expression. ${ }^{*} \mathrm{P}<0.05$; ${ }^{* * *} \mathrm{P}<0.01$. CDK, cyclin-dependent kinase; PI, propidium iodide.

expression were assessed in the present study. First, the vector containing NICD3 coding sequence was constructed. The results demonstrated that NICD3 expression significantly increased in 786-O and $\mathrm{ACHN}$ cells following transfection, by 47.0 and $168.1 \%$, respectively (Fig. 3A). To determine the effect of hypoxia on Notch3, the expression levels of the full length of Notch3 (Notch3FL), NICD3 with transmembrane domain (TD+NICD3) and NICD3 were detected via western
blotting.As the anti-Notch3 antibody used in this present study could bind with Human NOTCH3 aa 2300 to the C-terminus (C terminal), which Notch3FL, TD+NICD3 and NICD3 all contain, the bands of different molecular weights, $220 \mathrm{kDa}$, more than $90 \mathrm{kDa}$ and $90 \mathrm{kDa}$, relatively represented Notch3FL, TD+NICD3 and NICD3. The results demonstrated that the expression levels of Notch3FL, TD+NICD3 and NICD3 did not change in 786-O and ACHN cells following exposure to 

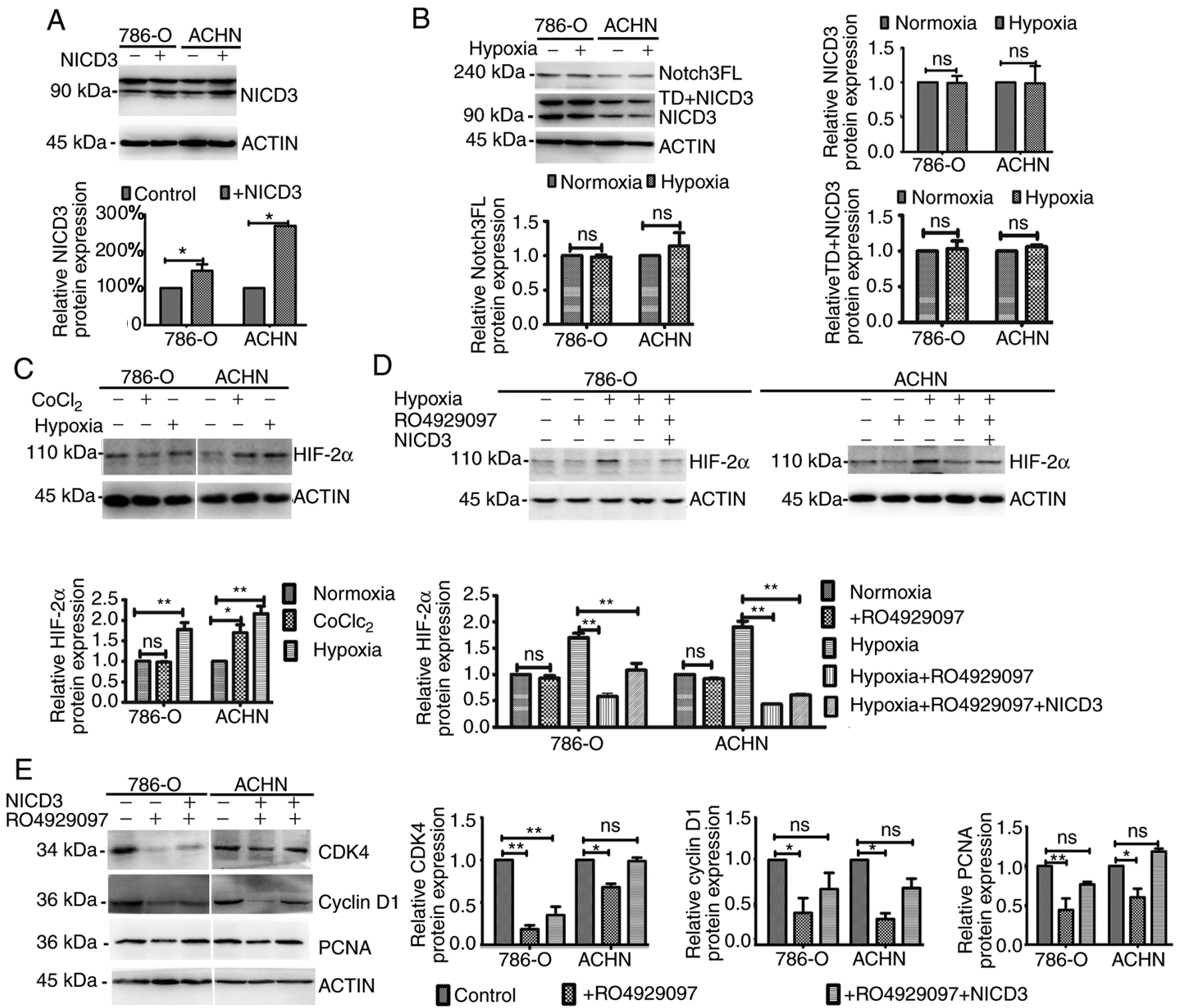

Figure 3. Western blot analysis following altered NICD3 expression. (A) NICD3 protein expression in 786-O and ACHN cells transfected with or without the vector containing the coding sequence of NICD3. Upper panels, representative blot images. N3ICD bands, $90 \mathrm{kDa}$ and TD+NICD3 bands, $>90 \mathrm{kDa}$. Lower panels, histograms of the relative protein expression. (B) Protein expression levels of Notch3FL, TD+NICD3 and NICD3 in 786-O and ACHN cells under $21 \% \mathrm{O}_{2}$ and $2 \% \mathrm{O}_{2}$ conditions. Upper left, representative blot images. Upper right and lower panels, histograms of the relative protein expression. (C) HIF-20 expression in 786-O and ACHN cells treated with $200 \mu \mathrm{M} \mathrm{CoCl}_{2}$ or $2 \% \mathrm{O}_{2}$. Upper panels, representative blot images. Lower panels, histograms of the relative protein expression. (D) HIF-2 $\alpha$ expression following altered NICD3 expression in normoxia or hypoxia. Upper panels, representative blot images. Lower panels, histograms of the relative protein expression. (E) CDK4, cyclin D1 and PCNA expression following altered NICD3 expression in hypoxia. Left panels, representative blot images. Right panels, histograms of the relative protein expression. ${ }^{*} \mathrm{P}<0.05 ;{ }^{* *} \mathrm{P}<0.01$. NICD3, Notch 3 intracellular domain; TD, transmembrane domain; FL, full length; HIF, hypoxia-inducible factor; CDK, cyclin-dependent kinase; PCNA, proliferating cell nuclear antigen; ns, non-significant.

$2 \% \mathrm{O}_{2}$ for $48 \mathrm{~h}$ (Fig. 3B). The effects of $\mathrm{CoCl}_{2}$ and $2 \% \mathrm{O}_{2}$ on HIF-2 $\alpha$ expression were subsequently assessed. As presented in Fig. $3 \mathrm{C}, 2 \% \mathrm{O}_{2}$, but not $\mathrm{CoCl}_{2}$, increased HIF-2 $\alpha$ expression in 786-O cells $(\mathrm{P}<0.01)$, whereas HIF- $2 \alpha$ expression increased in $\mathrm{ACNH}$ cells following treatment with both $\mathrm{CoCl}_{2}(\mathrm{P}<0.05)$ and $2 \% \mathrm{O}_{2}(\mathrm{P}<0.01)$, respectively. These results may be due to the inactivation of VHL in 786-O cells $(2,28)$. As presented in Fig. 3D, HIF-2 $\alpha$ expression was significantly decreased by RO4929097 under $2 \% \mathrm{O}_{2}$ (all $\mathrm{P}<0.01$ ), but not $21 \% \mathrm{O}_{2}$ for $48 \mathrm{~h}$, the effects of which were reversed following overexpression of NICD3 overexpression. Collectively, these results suggest that NICD3 affects HIF-2 $\alpha$ expression; however, hypoxia does not affect Notch3 expression.
To further investigate the association between hypoxia and Notch3 signaling, the effects of altered NICD3 expression on the cell cycle and proliferation-associated protein expression in hypoxia were assessed in the present study. Western blot analysis demonstrated that compared with the control groups, the protein levels of CDK4, cyclin D1 and PCNA decreased in RO4929097-treated 786-O and ACHN cells cultured under $2 \% \mathrm{O}_{2}($ all $\mathrm{P}<0.05)$, whereas NICD3 overexpression rescued the protein levels, suggesting that the hypoxia-induced protein expression was regulated by NICD3 (Fig. 3E). Taken together, the results of the present study suggest that regulation of NICD3 to these proteins is associated with its regulation to HIF- $2 \alpha$. 


\section{Discussion}

Notch family members are single-pass transmembrane proteins that function both as cell surface receptors and nuclear transcriptional regulators. The latter function is predominantly mediated by NICD. Upon Notch binding to their ligands, the extracellular subunit, NEC, dissociates from the transmembrane subunit (5). NEC is subsequently cleaved by a disintegrin, metalloprotease and $\gamma$-secretase, whereas the NICD is released into the cytoplasm and translocates into the nucleus to regulate the transcription of Notch target genes, which subsequently regulates proliferation and differentiation (6,31). In the present study, RO4929097 dose-dependently inhibited NICD3 expression in 787-O and ACHN cells, suggesting that RO4929097 downregulates Notch3 signaling.

Hypoxia and activation of HIFs have also been described in the major RCC subtypes, and are closely associated with ccRCC development and progression (4). In normoxia, HIF- $\alpha$ molecules are subjected to a regulatory process involving the enzymatic hypoxylation of conserved prolyl and asparaginyl residues, thus leading to VHL protein-mediated ubiquitination and proteasomal degradation (2). The HIF-specific prolyl hydroxylases have an iron-binding core, which can be replaced by $\mathrm{CoCl}_{2}$, resulting in the inhibition of HIF-1 $\alpha$ degradation; thus, $\mathrm{CoCl}_{2}$ is used to mimic chemical hypoxia effects (32). However, to the best of our knowledge, it has not yet been demonstrated that the function of cells in response to hypoxia can completely be recapitulated by $\mathrm{CoCl}_{2}$. In the present study, $\mathrm{CoCl}_{2}$ did not affect HIF-2 $\alpha$ protein expression in 786-O cells, which lack VHL (28). However, $2 \% \mathrm{O}_{2}$ increased HIF-2 $\alpha$ protein expression in 786-O and ACHN cells. These findings were consistent with the results that demonstrated that $2 \% \mathrm{O}_{2}$ promoted cell proliferation and cell cycle progression in 786-O and ACHN cells, suggesting that culturing cells in $2 \% \mathrm{O}_{2}$ for $48 \mathrm{~h}$ did induce the response of 786-O and ACHN cells to hypoxia in the present study. In D324 medulloblastoma cells, $\mathrm{CoCl}_{2}$ does not significantly alter HIF-2 $\alpha$ expression (33). Previous studies have demonstrated that hypoxia increases HIF-2 $\alpha$ protein expression in 786-O cells (34), and also increases cyclin D1 expression, which is a target gene of HIF-2 $\alpha$ (17). The results of the present study demonstrated that although the $\mathrm{CoCl}_{2}$ experimental group exhibited different results from $2 \% \mathrm{O}_{2}, 2 \% \mathrm{O}_{2}$ did affect ccRCC through its regulation of HIF-2 $\alpha$ expression.

Multiple signaling pathways, including the Notch signaling pathway, have been reported to affect the response to hypoxia and interact with HIFs at several levels (29,35-37). In the present study, although hypoxia did not affect Notch3 expression, NICD3 was demonstrated to regulate HIF-2 $\alpha$ protein expression, suggesting an association between Notch3 and HIF- $2 \alpha$ in ccRCCs. Furthermore, downregulation of NICD3 was demonstrated to decrease the proliferation of 787-O and ACHN cells under both normoxic and hypoxic conditions, suggesting the involvement of Notch3 in the progression of ccRCC in normoxia, and the response of ccRCC cells to hypoxia.

High cell proliferation is characterized by rapid cell division and $\mathrm{G}_{1}-\mathrm{S}$ transition $(16,24,25)$. A previous study demonstrated that Notch3 affects cell cycle progression (38). In esophageal squamous cell carcinoma, inhibiting Notch3 induces $G_{1}$ phase arrest and inhibits cell proliferation (39). In Notch-dependent
T-cell lymphomas, cyclin D3 and CDK4 are highly expressed, and $\gamma$-secretase inhibitor induces $G_{1}$ arrest in these cell lines (18). HIFs have also been reported to affect cell cycle progression through transcriptional targets, such as cyclin D1 and CDK inhibitors, p21 and p27 $(2,19,20)$. In the present study, RO4929097 treatment increased the number of cells in the $\mathrm{G}_{1}$ phase by downregulating the expression of cyclin D1 and CDK4 in normoxia and hypoxia, and the increased range of the percentage of cells in the $G_{1}$ phase induced by RO4929097 in hypoxia was higher compared with that in normoxia. Notably, overexpression of NICD3 reversed the RO4929097-induced downregulated expression of cyclin D1 and CDK4 in hypoxia. Taken together, these results suggest that Notch3 promotes cell cycle progression of ccRCCs by regulating cyclin D1 and CDK4 expression, and acts synergistically with HIFs to regulate cyclin D1 and CDK4 expression in hypoxia.

In conclusion, the results of the present study demonstrated that Notch3 is closely associated with the cell proliferation of ccRCC cells through its regulatory effects on the cell cycle, and by acting synergistically with HIF- $2 \alpha$ in hypoxia. These findings provide novel insights into targeting Notch3 as a promising therapeutic option in RCC. However, the exact molecular mechanisms underlying the synergistical effect of Notch 3 and HIF- $2 \alpha$ on ccRCC tumorigenesis and progression were not investigated in the present study, and further investigations are required.

\section{Acknowledgements}

The authors would like to thank Dr Ying Zhang and Dr Miao Yu (Center of Science Experiments, China Medical University, Shenyang, China) for their technical assistance with the flow cytometer.

\section{Funding}

The present study was funded by The Scientific Research Fund of Liaoning Science and Technology Department, Shenyang, China (grant no. 20180551143).

\section{Availability of data and materials}

The datasets used and/or analyzed during the current study are available from the corresponding author on reasonable request.

\section{Authors' contributions}

$\mathrm{QH}, \mathrm{CL}$ and BW conceived and designed the present study. $\mathrm{QH}, \mathrm{YF}, \mathrm{FH}, \mathrm{BL}, \mathrm{JX}, \mathrm{WS}, \mathrm{DH}$ and HK performed the experiments, and $\mathrm{QH}$ drafted the initial manuscript, analyzed and interpreted the data, and performed statistical analysis. CL and $\mathrm{BW}$ revised the manuscript for intellectual content. All authors read and approved the manuscript and agreed to be accountable for all aspects of the research in ensuring that the accuracy or integrity of any part of the work are appropriately investigated and resolved.

\section{Ethics approval and consent to participate}

Not applicable. 


\section{Patient consent for publication}

Not applicable.

\section{Competing interests}

The authors declare that they have no competing interests.

\section{References}

1. Bergerot P, Lamb P, Wang E and Pal SK: Cabozantinib in combination with immunotherapy for advanced renal cell carcinoma and urothelial carcinoma: Rationale and clinical evidence. Mol Cancer Ther 18: 2185-2193, 2019.

2. Baba M, Hirai S, Yamada-Okabe H, Hamada K, Tabuchi H, Kobayashi K, Kondo K, Yoshida M, Yamashita A, Kishida T, et al Loss of von hippel-lindau protein causes cell density dependent deregulation of cyclinD1 expression through hypoxia-inducible factor. Oncogene 22: 2728-2738, 2003.

3. Rajendran JG, Mankoff DA, O'Sullivan F, Peterson LM, Schwartz DL, Conrad EU, Spence AM, Muzi M, Farwell DG and Krohn KA: Hypoxia and glucose metabolism in malignant tumors: Evaluation by $\left[{ }^{18} \mathrm{~F}\right]$ fluoromisonidazole and $\left[{ }^{18} \mathrm{~F}\right]$ fluorodeoxyglucose positron emission tomography imaging. Clin Cancer Res 10: 2245-2252, 2004

4. Schödel J, Grampp S, Maher ER, Moch H, Ratcliffe PJ, Russo P and Mole DR: Hypoxia, hypoxia-inducible transcription factors, and renal cancer. Eur Urol 69: 646-657, 2016.

5. Artavanis-Tsakonas S, Matsuno K and Fortini ME: Notch signaling. Science 268: 225-232, 1995.

6. Artavanis-Tsakonas S, Rand MD and Lake RJ: Notch signaling: Cell fate control and signal integration in development. Science 284: 770-776, 1999.

7. Bhagat TD, Zou Y, Huang S, Park J, Palmer MB, Hu C, Li W, Shenoy N, Giricz O, Choudhary G, et al: Notch pathway is activated via genetic and epigenetic alterations and is a therapeutic target in clear cell renal cancer. J Biol Chem 292: 837-846, 2017.

8. Jedroszka D, Orzechowska M and Bednarek AK: Predictive values of notch signalling in renal carcinoma. Arch Med Sci 13 1249-1254, 2017

9. Fendler A, Bauer D, Busch J, Jung K, Wulf-Goldenberg A, Kunz S, Song K, Myszczyszyn A, Elezkurtaj S, Erguen B, et al: Inhibiting WNT and NOTCH in renal cancer stem cells and the implications for human patients. Nat Commun 11: 929, 2020.

10. Hosseini-Alghaderi S and Baron M: Notch3 in development, health and disease. Biomolecules 10: 485, 2020.

11. Olsauskas-Kuprys R, Zlobin A and Osipo C: Gamma secretase inhibitors of notch signaling. Onco Targets Ther 6: 943-955, 2013.

12. Sonnenschein C and Soto AM: Symposium on the control of cell proliferation and cancer. Cancer Res 49: 6161, 1989.

13. Hubbi ME and Semenza GL: Regulation of cell proliferation by hypoxia-inducible factors. Am J Physiol Cell Physiol 309: C775-C782, 2015

14. Katz D, Ito E, Lau KS, Mocanu JD, Bastianutto C, Schimmer AD and Liu FF: Increased efficiency for performing colony formation assays in 96-well plates: Novel applications to combination therapies and high-throughput screening. Biotechniques 44: ix-xiv, 2008.

15. Braselmann H, Michna A, Heß J and Unger K: CFAssay: Statistical analysis of the colony formation assay. Radiat Oncol 10: 223, 2015

16. Evan GI and Vousden KH: Proliferation, cell cycle and apoptosis in cancer. Nature 411: 342-348, 2001.

17. Raju RR, Lau KW, Tran MG, Sowter HM, Mandriota SJ, Li JL, Pugh CW, Maxwell PH, Harris AL and Ratcliffe PJ: Contrasting properties of hypoxia-inducible Factor 1 (HIF-1) and HIF-2 in von hippel-lindau-associated renal cell carcinoma. Mol Cell Biol 25: 5675-5686, 2005

18. Joshi I, Minter LM, Telfer J, Demarest RM, Capobianco AJ, Aster JC, Sicinski P, Fauq A, Golde TE and Osborne BA: Notch signaling mediates $\mathrm{G} 1 / \mathrm{S}$ cell-cycle progression in $\mathrm{T}$ cells via cyclin D3 and its dependent kinases. Blood 113: 1689-1698, 2009.
19. Gardner LB, Li Q, Park MS, Flanagan WM, Semenza GL and Dang CV: Hypoxia inhibits G1/S transition through regulation of p27 expression. J Biol Chem 276: 7919-7926, 2001.

20. Green SL, Freiberg RA and Giaccia AJ: P21(Cip1) and p27(Kip1) regulate cell cycle reentry after hypoxic stress but are not necessary for hypoxia-induced arrest. Mol Cell Biol 21: 1196-1206, 2001.

21. Chen J, Imanaka N, Chen J and Griffin JD: Hypoxia potentiates notch signaling in breast cancer leading to decreased E-cadherin expression and increased cell migration and invasion. Br J Cancer 102: 351-360, 2010.

22. Michalides R: Prognosis for G1 cell-cycle regulators: Useful for predicting course of disease and for assessment of therapy in cancer. J Pathol 188: 341-343, 1999.

23. Milde-Langosch K and Riethdorf S: Role of cell-cycle regulatory proteins in gynecological cancer. J Cell Physiol 196: 224-244, 2003.

24. He L, Lu N, Dai Q, Zhao Y, Zhao L, Wang H, Li Z, You Q and Guo Q: Wogonin induced G1 cell cycle arrest by regulating wnt $/ \beta$-catenin signaling pathway and inactivating CDK8 in human colorectal cancer carcinoma cells. Toxicology 312: 36-47, 2013.

25. Wang J, Li Q, Yuan J, Wang J, Chen Z, Liu Z, Li Z, Lai Y, Gao J and Shen L: CDK4/6 inhibitor-SHR6390 exerts potent antitumor activity in esophageal squamous cell carcinoma by inhibiting phosphorylated $\mathrm{Rb}$ and inducing G1 cell cycle arrest. J Transl Med 15: 127, 2017.

26. Salama R, Masson N, Simpson P, Sciesielski LK, Sun M, Tian YM, Ratcliffe PJ and Mole DR: Heterogeneous effects of direct hypoxia pathway activation in kidney cancer. PLoS One 10: e0134645, 2015.

27. Shen $\mathrm{C}$ and Kaelin WG Jr: The VHL/HIF axis in clear cell renal carcinoma. Semin Cancer Biol 23: 18-25, 2013.

28. Shinojima T, Oya M, Takayanagi A, Mizuno R, Shimizu N and Murai M: Renal cancer cells lacking hypoxia inducible factor (HIF)-1 $\alpha$ expression maintain vascular endothelial growth factor expression through HIF-2 $\alpha$. Carcinogenesis 28: 529-536, 2007.

29. De Francesco EM, Maggiolini M and Musti AM: Crosstalk between notch, HIF-1 $\alpha$ and GPER in breast cancer EMT. Int J Mol Sci 19: 2011, 2018.

30. Marignol L, Rivera-Figueroa K, Lynch $\mathrm{T}$ and Hollywood D: Hypoxia, notch signalling, and prostate cancer. Nat Rev Urol 10: 405-413, 2013.

31. Kandasamy K, Mohan SS, Raju R, Keerthikumar S, Kumar GS, Venugopal AK, Telikicherla D, Navarro JD, Mathivanan S, Pecquet C, et al: NetPath: A public resource of curated signal transduction pathways. Genome Biol 11: R3, 2010.

32. Yuan Y, Hilliard G, Ferguson T and Millhorn DE: Cobalt inhibits the interaction between hypoxia-inducible factor-alpha and von hippel-lindau protein by direct binding to hypoxia-inducible factor-alpha. J Biol Chem 278: 15911-15916, 2003.

33. Mutvei AP, Landor SK, Fox R, Braune EB, Tsoi YL, Phoon YP, Sahlgren C, Hartman J, Bergh J, Jin S, et al: Notch signaling promotes a HIF $2 \alpha$-driven hypoxic response in multiple tumor cell types. Oncogene 37: 6083-6095, 2018.

34. Zimmer M, Ebert BL, Neil C, Brenner K, Papaioannou I, Melas A, Tolliday N, Lamb J, Pantopoulos K, Golub T and Iliopoulos O: Small molecule inhibitors of HIF-2a translation link its 5'-UTR iron-responsive element (IRE) to oxygen sensing. Mol Cell 32: 838-848, 2008

35. Kong LY, Xi Z, Ma WT, Yang FY, Niu LD and Shi JH: Effects of notch signal on the expressions of HIF- $\alpha$ and autophagy-related genes BECLIN1, LC3I, LC3II in oxygen-glucose deprivation induced myocardial cell injury. Zhongguo Ying Yong Sheng Li Xue Za Zhi 35: 165-168, 2019 (In Chinese).

36. Yu N, Wu JL, Xiao J, Fan L, Chen SH and Li W: HIF-1 $\alpha$ regulates angiogenesis via notch1/STAT3/ETBR pathway in trophoblastic cells. Cell Cycle 18: 3502-3512, 2019.

37. Moriyama H, Moriyama M, Ozawa T, Tsuruta D, Iguchi T, Tamada S, Nakatani T, Nakagawa K and Hayakawa T: Notch signaling enhances stemness by regulating metabolic pathways through modifying p53, NF- $\kappa B$, and HIF-1 $\alpha$. Stem Cells Dev 27: 935-947, 2018.

38. Dang TP: Notch, apoptosis and cancer. Adv Exp Med Biol 727: 199-209, 2012

39. Lu Z, Ren Y, Zhang M, Fan T, Wang Y, Zhao Q, Liu HM, Zhao W and Hou G: FLI-06 suppresses proliferation, induces apoptosis and cell cycle arrest by targeting LSD1 and Notch pathway in esophageal squamous cell carcinoma cells. Biomed Pharmacother 107: 1370-1376, 2018. 